\title{
ERRATUM
}

W. J. Theuvenet $\cdot$ C. E. Essed $\cdot$ F. Eggelmeijer

G. M. Alink

\section{Tenosynovitis caused by Pyracantha coccinea thorn injury of the hand}

Published online: 3 July 2001

(C) Springer-Verlag 2001

\section{Eur J Plast Surg (2000) 23:214-216}

In the above article unfortunately the wrong key words were published.

The correct key words are: Tenosynovitis - Thorn injury - Fire thorn - Pyracantha coccinea.

We sincerely apologize for this error.

W.J. Theuvenet $(\square)$

Lukas Hospital ZCA, Department of Plastic,

Reconstructive and Hand Surgery, Koninginnelaan 23,

7315 BK Apeldoorn, The Netherlands

e-mail: wjtheuvenet@wxs.nl

Tel.: +31-55-5818265, Fax: +31-55-5818999

C.E. Essed

Department of Pathology, Lukas Hospital ZCA,

Apeldoorn, The Netherlands

F. Eggelmeijer

Department of Rheumatology, Lukas Hospital ZCA,

Apeldoorn, The Netherlands

G.M. Alink

Department of Toxicology,

Agricultural University of Wageningen, The Netherlands 